\title{
Massive hematemesis in a child with undiagnosed aortic coarctation and mycotic aneurysm
}

\author{
Peter Grant, MBBS (Hon), FRACS, MBA, ${ }^{a}$ John Santosh Kumar Murala, MBBS, MS, MCh, ${ }^{a}$ Rao Kolli, MBBS, FRACP,

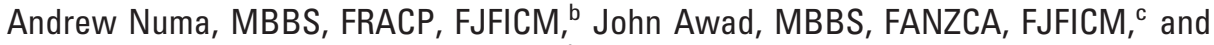 \\ Anthony Vincent Dilley, MBBS, FRACS, ${ }^{d}$ Randwick, NSW, Australia
}

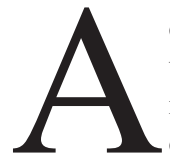

ortoesophageal fistula (AEF) is a rare cause of upper gastrointestinal bleeding. Most cases are identified postmortem after an exsanguinating hemorrhage. We report a case of massive hematemesis caused by a ruptured mycotic aneurysm (MA) in a child with undiagnosed coarctation of the aorta, which was managed successfully. To our knowledge this is the first reported successful outcome of a ruptured MA in a de novo coarctation causing $\mathrm{AEF}$ in a child.

\section{Clinical Summary}

An 11-year-old boy presented with a 1-week history of fever, hematuria, and painful rash on the feet (Figure 1). He was provisionally treated for acute glomerulonephritis. Soon after admission, the boy demonstrated a massive hematemesis of $2 \mathrm{~L}$ and cardiac arrest. He was promptly resuscitated. His chest x-ray film showed deviation of the Ryles tube, indicative of a mediastinal mass (Figure 2, A). Endoscopy revealed a large clot in the upper third of the esophagus. Computed tomography of the thorax showed a hematoma around the midthoracic aorta (Figure 2, B). He was transferred to our hospital. Aortic MA with AEF and a patent ductus or coarctation were considered; however, absent femoral pulses indicated the latter.

Urgent surgery was performed through a clamshell incision. Cardiopulmonary bypass was established through right atrial and ascending aorta cannulation. The patient was cooled to $18^{\circ} \mathrm{C}$. Clamps were placed on the aorta proximally and distally to the inflammatory mass. The infected aorta was incised vertically. A juxtaductal coarctation was noted with a 5-mm lumen, and immediately distal to this area a $4 \times 4-\mathrm{cm}$ false aneurysm was present with extensive clot and pus. There was a $2.5-\mathrm{cm}$ vertical communication into the esophagus. The coarctation segment and infected aortic segment were resected, and a 14-mm polytetrafluoroethyl-

From the Departments of Cardiothoracic Surgery, ${ }^{a}$ Children's Intensive Care, ${ }^{\mathrm{b}}$ Pediatric Cardiac Anesthesia, ${ }^{\mathrm{c}}$ and Pediatric Surgery ${ }^{\mathrm{d}}$ of Sydney Children's Hospital, Randwick, NSW, Australia.

Received for publication Aug 1, 2006; accepted for publication Aug 7, 2006.

Address for reprints: Peter Grant, MBBS (Hon), FRACS, MBA, Department of Cardiothoracic Surgery, Sydney Children's Hospital, High Street, Randwick, NSW, Australia 2031 (E-mail: peter.grant@sesiahs.health.nsw.gov.au).

J Thorac Cardiovasc Surg 2006;132:1482-3

$0022-5223 / \$ 32.00$

Copyright $\odot 2006$ by The American Association for Thoracic Surgery doi:10.1016/j.jtcvs.2006.08.027

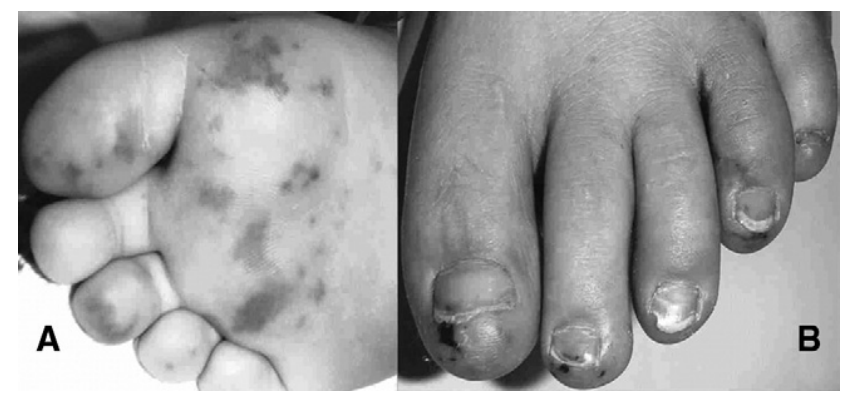

Figure 1. Petechial hemorrhages (A) and splinter hemorrhages (B) secondary to septic embolus.

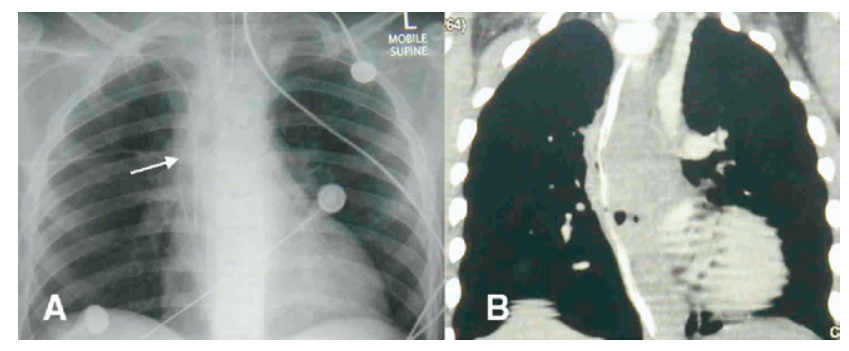

Figure 2. A, Chest x-ray film showing rightward deviation of the Ryles tube with widened mediastinum. B, Coronal section of the computed tomography of the chest showing a large hematoma with a thin rim of contrast.

ene (Gore-Tex, WL Gore and Associates, Newark, NJ) interposition graft was used.

The esophageal perforation was closed directly, and the omentum was wrapped around it and the graft. The patient had a supportive stamm gastrostomy.

Blood cultures grew a sensitive Staphylococcus aureus. The patient recovered and was discharged from the hospital after 4 weeks. Intravenous antibiotics were continued for a further 6 weeks and oral antibiotics thereafter. At the 8-month follow-up, he was well.

\section{Discussion}

Infective endocarditis as a complication of coarctation of the aorta, causing aortic endarteritis, and thus MA, is rare in the present era. More common causes of aortic endarteritis in children include iatrogenic umbilical artery catheter sepsis (35 cases reported) and 
complications of surgery for congenital anomalies, especially after patch repair of coarctation aorta. ${ }^{1}$

In the natural history of aortic coarctation, aortic endarteritis was responsible for approximately $20 \%$ of deaths in the presurgical era. ${ }^{2}$ A literature search revealed 26 reported cases of MA in patients with coarctation between 1965 and 2005. Of these, 1 child died of AEF. ${ }^{3}$

The high-velocity blood jet initiates the endothelial trauma that encourages microbial adhesion and thus vegetations distal to the site of coarctation (as seen on the pulmonary artery opposite the jet from a patent ductus). ${ }^{2}$

Although AEF was first reported in 1818, and Chiari's triad of midthoracic pain, sentinel arterial hemorrhage, hematemesis, and finally exsanguination after a symptom-free interval was described in 1914, the diagnosis is rarely made before death, and before 1983 no one survived surgery. ${ }^{3}$

No child with AEF survived medical management, and there are only 8 reported survivors after surgery. Five cases were secondary to congenital vascular rings with prolonged nasogastric intubation, and 3 cases were secondary to foreign body aspiration. ${ }^{4}$ The AEF occurs as the result of chronic pressure causing erosion and ischemic necrosis of the esophagus.

The management of AEF in children is challenging. The notoriously poor wound healing of the esophagus makes the repair more difficult. We believe that extensive debridement of all infected tissues, antibiotic irrigation, and careful anastomosis of the esophagus and omentopexy helped in the recovery of our patient.

Children with MA commonly grow Gram-positive organisms (Staphylococcus) in $86 \%$ of cases, Gram-negative organisms (Escherichia coli, Pseudomonas, Klebsiella) in $21 \%$ of cases, and fungi in $3 \%$ of cases. ${ }^{1}$
With no guidelines for antibiotic therapy in children and in view of the consequences of reinfection, we recommend continuing the antibiotics for an indefinite period. Chan and colleagues 5 recommend lifelong antibiotic coverage in adults with MA, and they reported recurrence in 2 patients who discontinued antibiotics.

\section{Conclusions}

Aortic endarteritis subsequent to coarctation of aorta is a devastating complication. This case demonstrates that with prompt resuscitation, a high index of suspicion, expeditious surgery, and multidisciplinary postoperative care, some patients can survive. The duration of antibiotic therapy remains a dilemma. These patients require lifelong follow-up.

We acknowledge Mr. Daminda Weerasinghe for the photographs.

\section{References}

1. Cribari C, Meadors FA, Crawford ES, Coselli JS, Safi HJ, Svensson LG Thoracoabdominal aortic aneurysm associated with umbilical artery catheterization: case report and review of the literature. J Vasc Surg. 1992;16:75-86.

2. Jenkins NP, Ward C. Coarctation of the aorta: natural history and outcome after surgical treatment. QJM. 1999;92:365-71.

3. Bogey WM, Thomas JH, Hermreck AS. Aortoesophageal fistula: report of a successfully managed case and review of the literature. J Vasc Surg. 1992;16:90-5.

4. Sigalet DL, Laberge JM, Di Lorenga M, Adolph V, Nguyen LT, Youssef S, et al. Aortoesophageal fistula: congenital and acquired causes. J Pediatr Surg. 1994;29:1212-4.

5. Chan FY, Crawford ES, Coselli JS, Safi HJ, William TW Jr. In situ prosthetic graft replacement for mycotic aneurysms of the aorta. Ann Thorac Surg. 1989;47:193-203. 